\title{
STRENGTH \& STABILITY CONSIDERATIONS IN ALLOY FORMULATION
}

\author{
Graham Durber ${ }^{\dagger}$ \\ Howmet Ltd., Exeter Alloy \\ England
}

\begin{abstract}
It is recognised that the development of new alloys requires the commitment of increasingly large amounts of money and time which few corporations can these days afford. Techniques for short-cutting the development path are needed, e.g. predictive models. Two such methods are presented here for pre-determining alloy stability and strength. The pursuit of this and similar approaches should help to minimise the expense, and time, incurred in manufacturing and testing many unsuccessful alloy formulations. New alloys are still needed with property combinations which have yet to be realised.
\end{abstract}

\section{Introduction}

New alloy design has traditionally required the assessment of multiple alloy formulations, which incurs considerable cost and time. However, it is reasoned that there exists sufficient non-proprietary data on a large number of superallnys for it to be feasible to estimate, at least to a first approximation, the likely strength of an alloy based on a consideration of its chemical composition and structure. The relationship between chemistry and other material properties such as corrosion resistance, castability and hottear resistance remains publically less well defined. Neither does alloy stability appear entirely predictable. Given the number of stability calculations that are routinely run to make such a determination, this statement may sound a little surprising. Particularly so when one considers that the development of the superalloys, from the simple precipitation hardened $\mathrm{Ni}-\mathrm{Cr}$ system to those of today, where a high proportion of solid-solution strengtheners are used, has only been achieved by a careful balancing of strength versus microstructural stability.

A method that was developed in the 1960's and still used today for determining freedom from intermetallic phases such as $\sigma, \mu \& \chi$ phases is called "Phacomp" $(1,2)$. A critical electron vacancy or " $\mathrm{N}_{\mathrm{v}}$ " value is determined for an alloy, below which it is judged stable over a set time and temperature. The problem with this system however is that a unique critical limit has to be established for each alloy that is assessed. This calculation is continually being refined with regard to the compositions of the various phases. More recently a modified approach involving the "d-electrons concept" (3) for SC alloy design has been extended to include also a measure of the bond strength of the alloying elements (4). In this way, the relative stability of an alloy could be displayed on a map, but the boundaries remain undefined

\section{Electronic \& Crystal Structures}

Many of the physical properties of the transition metals (e.g. melting point, strength, high specific heat) can be explained by the ease with which electrons can be deflected from the outer shell orbitals into vacant d-states. This ability to absorb valency electrons enables alloys of the transition metals to exhibit a wide range of stability for a given crystal structure. It should be possible therefore to construct a map of crystal structure in a manner similar to the periodic table of elements, except that the two axes become the $(s+p)$ and (d) orbital electron levels rather than elemental group and period. This has been done for the transition elements and its form is shown in Figure 1.

Within this figure a "ternary" boundary for Ni-Co-Cr can be seen, shown by the dotted lines, with $\mathrm{Ni}$ residing at the top right hand corner and $\mathrm{Cr}$ at the bottom. This ternary area is different however from a normal phase diagram in that allowance can be made for any element in the alloy. Alloy location within this field depends only on the summation of the $\left(s^{+} p\right) \&$ (d) electrons in the residual matrix, having made due allowance for phase precipitation in the normal way as in any Phacomp calculation. The preferred crystal structure changes within this ternary area from fcc to $\mathrm{fcc} / \mathrm{hcp}$, depending on size factor considerations, to hcp as 


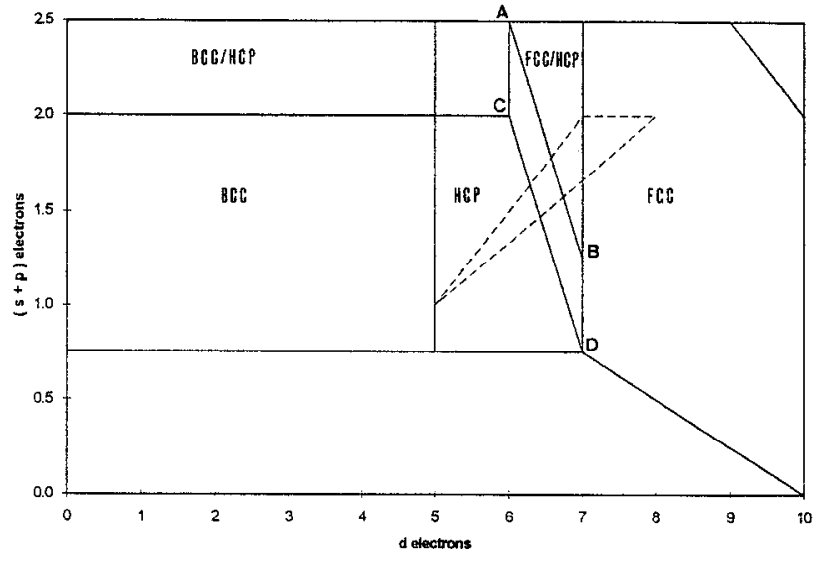

Fig. 1: Crystal structure map in relation to $\left(s^{+} \mathrm{p}\right)$ and (d) electrons. The dotted lines represent the ternary boundary for $\mathrm{Ni}-\mathrm{Cr}-\mathrm{Co}$, as read clockwise from the top right hand corner.

alloy location moves away from the nickel towards the chromium position. The lines $\mathrm{AB} \& \mathrm{CD}$ represent contours of constant electron hole numbers running across the ternary field.

The location of a number of cast superalloys (IN100, IN738LC, IN792mod5A, SRR99, Mar-M002, GTD111, CMSX4, R80) on this "d-stable" diagram is shown in Figure 2. With the exception of $\mathrm{IN} 100$, all of these plus many other superalloys lie within the quadrant EFGH.

The higher strength alloys amongst those displayed in Figure 2 tend towards the mid-span of the EF boundary. The lower strength alloys fall towards the lower quarter of the quadrant, towards the EH boundary. Many of the older

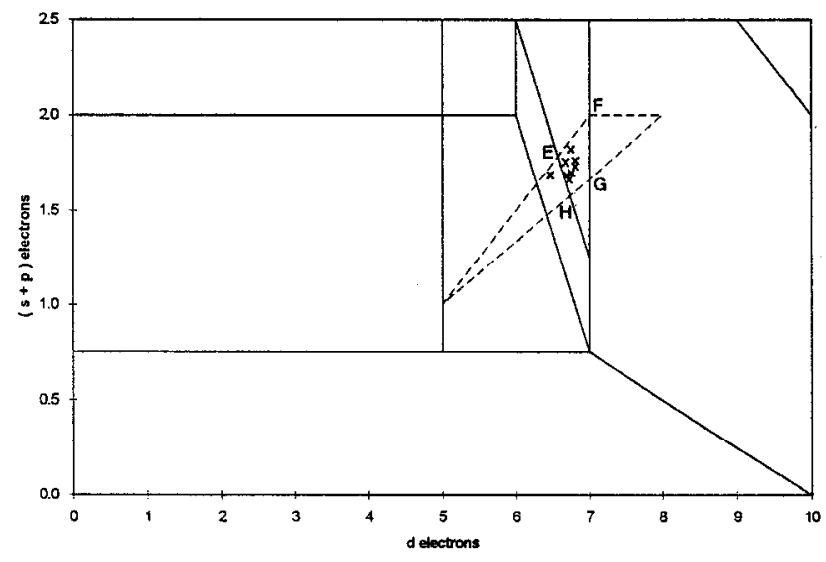

Fig. 2: Positioning of various cast superalloys on the d-stable map

alloys fall in this area, and tend to have their aim chemistries adjusted to the limit of their maximum permissible Phacomp value, to maximise stress-rupture strength, e.g. IN738LC. From a consideration of favoured crystal structure, alloy stability is expected to improve as location moves away from the EH boundary towards the FG boundary.

\section{Stress-Rupture Strength Prediction}

For the purpose of this evaluation, the creep strength of a superalloy is presumed to be controlled by the normal power law creep equation, plus a factor for alloy chemistry.

Table I Alloy Chemistries (Weight \%)

\begin{tabular}{|l|l|l|l|l|l|l|l|l|l|l|l|l|l|l|}
\hline & $\mathrm{C}$ & $\mathrm{Al}$ & $\mathrm{B}$ & $\mathrm{Co}$ & $\mathrm{Cr}$ & $\mathrm{Hr}$ & $\mathrm{Mo}$ & $\mathrm{Nb}$ & $\mathrm{Re}$ & $\mathrm{Ta}$ & $\mathrm{Ti}$ & $\mathrm{V}$ & $\mathrm{W}$ & $\mathrm{Zr}$ \\
\hline IN713LC & .05 & 6.0 & .01 & & 12.0 & & 4.2 & 2.0 & & & 0.7 & & & .06 \\
\hline IN738LC & .10 & 3.5 & .01 & 8.3 & 16.0 & & 1.7 & 0.9 & & 1.7 & 3.4 & & 2.6 & .05 \\
\hline IN100 & .16 & 5.5 & .014 & 15.0 & 10.0 & & 3.0 & & & & 4.7 & 1.0 & & .06 \\
\hline IN939 & .15 & 1.9 & .01 & 19.0 & 22.5 & & & 1.0 & & 1.4 & 3.7 & & 2.0 & .09 \\
\hline IN792.5A & .08 & 3.4 & .015 & 9.0 & 12.5 & & 1.9 & & & 4.0 & 3.8 & & 4.0 & .02 \\
\hline MarM002 & .14 & 5.7 & .015 & 10.0 & 8.9 & 1.5 & & & & 2.5 & 1.5 & & 10.0 & .04 \\
\hline SRR99 & .02 & 5.5 & & 5.0 & 8.6 & & & & & 2.8 & 2.2 & & 9.5 & \\
\hline CMSX-4@ & & 5.7 & & 9.6 & 6.4 & 0.1 & 0.6 & & 2.9 & 6.5 & 1.0 & & 6.4 & \\
\hline R77 & .05 & 4.3 & .015 & 14.5 & 14.6 & & 4.2 & & & & 3.3 & & & .04 \\
\hline Nim80 & .06 & 1.4 & .003 & & 19.5 & & & & & & 2.4 & & & .06 \\
\hline Nim90 & .07 & 1.5 & .003 & 16.5 & 19.5 & & & & & & 2.5 & & & .06 \\
\hline MarM0011 & .14 & 5.5 & .015 & 10.0 & 8.3 & 1.5 & 0.7 & & & 3.0 & 1.0 & & 10.0 & .05 \\
\hline U500 & .07 & 3.0 & .008 & 18.0 & 19.0 & & 4.0 & & & & 3.0 & & & .05 \\
\hline
\end{tabular}

CMSX-4 is a Cannon-Muskegon alloy 
Thus $\varepsilon=$ A. $f($ chemistry $) \cdot(\sigma / E)^{\mathrm{n}} \cdot \exp (-\mathrm{Q} / \mathrm{RT})$

And

$$
\mathrm{t}_{\mathrm{r}} \approx \mathrm{B} / \varepsilon
$$

where $\varepsilon$ is the steady state creep rate at an applied stress $\sigma$, and $t_{r}$ is the rupture life. $E$ is the Young's modulus, $Q$ is the apparent activation energy, $R$ the gas constant and $T$ the absolute temperature. A \& $\mathrm{B}$ are constants. If $f$ (chemistry) can be described in simple terms of alloy chemistry, then the strength of a new superalloy formulation can be largely predicted in advance of its manufacture.

By selecting an alloy data-base which contained a broad weight percentage range for the alloying elements and a broad spread in alloy strengths, the attempt was made to correlate alloy chemistry and strength. The alloy data-base that was chosen for this exercise is shown in Table I.

A Larson-Miller parameter $P(200 M P a)$ actual was determined for each alloy using stress-rupture data taken from various published sources. These values are shown in Table II.

Table II Larson-Miller Parameters, based on $1000 \mathrm{~h}$ Stress-Rupture Data.

\begin{tabular}{|l|l|l|}
\hline Alloy & $\begin{array}{l}\text { Actual } \\
\mathrm{P}(200 \mathrm{MPa})\end{array}$ & $\begin{array}{l}\text { Calculated } \\
\mathrm{P}(200 \mathrm{MPa})\end{array}$ \\
\hline Nimocast 80 & 22.60 & 22.43 \\
Nimocast 90 & 23.84 & 23.88 \\
U500 & 25.50 & 25.44 \\
IN713LC & 26.25 & 26.19 \\
IN939 & 26.26 & 26.07 \\
IN738LC & 26.33 & 26.27 \\
R77 & 26.45 & 26.26 \\
IN100 & 26.90 & 26.87 \\
IN792mod5A & 27.30 & 27.32 \\
Mar-M-002 & 27.10 & 27.24 \\
DS Mar-M-002 & 27.35 & 27.35 \\
Mar-M-0011 & 27.40 & 27.36 \\
SRR99 & 28.15 & 28.18 \\
CMSX-4@ & 28.90 & 28.93 \\
\hline
\end{tabular}

Table II also shows P(200MPa) calculated figures. These were obtained from multiple regression analysis of alloy chemistry (atomic percent) versus the $P(200 \mathrm{MPa})$ actual data.
The linear regression obtained between the calculated and real values is in excess of 0.99 . The biggest error is below $1 \%$ and typically it is better than $0.5 \%$. This correlation was achieved by using the multiplication factors for the alloying elements as shown in Table III, plus the following equation:

$P(20 O M P a)$ calc $=21.37+0.166 \Sigma\left(\mathrm{M}_{\mathrm{n}} \cdot \mathrm{A}_{\mathrm{n}}\right)+$ structure

where $M_{n}$ is the multiplication factor for the $n^{\text {th }}$ element and $A_{n}$ is the atomic traction of that same element. The incorporation of a structure factor to allow for the obvious differences between SC \& DS versus equi-axed alloys assists the correlation.

The data presented in Table III is of course not definitive; the individual coefficients that are obtained will depend on the choice of alloys for the data-base. Different selections of alloys have been examined and it was found that variations were minor for most elements. As might be expected, fluctuations were greatest for carbon and boron. If only equi-axed alloys are considered, then the influences of these two elements greatly diminishes. Zirconium remains a very positive influence.

The weightings attributed in Table III to the 1st long period of elements ( $\mathrm{Ti}, \mathrm{V}, \mathrm{Cr}, \& \mathrm{Co}$ ) follow a similar dependency on $(d+s)$ electrons as does the atomic volume (5) of these elements, i.e. atomic size differences could be contributing to the strengthening mechanisms. Continuing with this comparison, the 2nd \& 3rd long period series of elements $(\mathrm{Zr}, \mathrm{Nb}, \mathrm{Mo} \& \mathrm{Hf}, \mathrm{Ta}, \mathrm{W}, \mathrm{Re}$ ) would be expected to show much higher weightings, as is indeed the case but for the exception of hafnium. The anomalous influence of this element on strength has been observed before (6)

The $P(200 M P a)$ calculated value of an alloy provides the first step in the determination of that particular alloy's $f$ (chemistry) function. It was found that the actual LarsonMiller curves for the alloys investigated were best described by the dependency:

$\mathbf{t}_{\mathrm{r}}=f($ chemistry $) /\left\{\sigma^{(\mathrm{A}+\mathrm{BT} / \sigma)} \cdot \exp [-(\mathrm{Q}+\mathrm{CT}) / \mathrm{RT}]\right.$

where $A, B, \& C$ are constants

The stress exponent follows an inverse function of stress, Figure 3. The slight change in position of the curve from one alloy to another is a result of the temperature dependence of this factor. The apparent activation energy in

Table III Multiplication Factors used with Atomic Percentages of the Alloying Elements to produce $P(200 \mathrm{MPa})$ Calculated.

\begin{tabular}{|l|l|l|l|l|l|l|l|}
\hline $\mathrm{C}$ & $\mathrm{Al}$ & $\mathrm{B}$ & $\mathrm{Co}$ & $\mathrm{Cr}$ & $\mathrm{Hf}$ & $\mathrm{Mo}$ & $\mathrm{Nb}$ \\
\hline-15.5 & 1.4 & 15.5 & 0.67 & -0.26 & -0.6 & 1.9 & 8.5 \\
\hline $\mathrm{Re}$ & $\mathrm{Ta}$ & $\mathrm{Ti}$ & $\mathrm{V}$ & $\mathrm{W}$ & $\mathrm{Zr}$ & $\begin{array}{l}\mathrm{DS} \\
\text { SC }\end{array}$ & \\
1.0 & 4.4 & 3.0 & 1.0 & 3.9 & 70 & 0.2 & \\
\hline
\end{tabular}




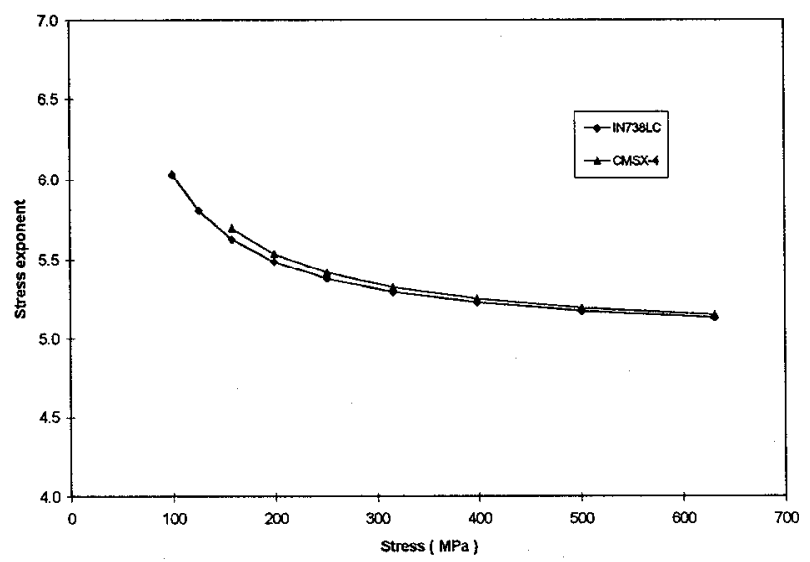

Fig.3 Variation of the stress exponent with stress. The slight shift in the curve from one alloy to another is a result of the temperature dependency of this factor.

equation 4 is linearly dependent on temperature, Figure 4. The final positions of the calculated curves were determined by inserting the calculated $t_{r}$ values from equation 4 into equation 5 with $f$ (chemistry) assuming a value making $\mathbf{P}_{\mathrm{f}}$ (a) $200 \mathrm{MPa}=P(200 \mathrm{MPa})$ calculated $\}$

$$
\mathrm{P}_{\mathrm{f}}=\mathrm{T} \cdot\left\{20+\log \left(\mathrm{t}_{\mathrm{r}}\right)\right\}
$$

The results of this excercise can be seen in Figure 5, which compares actual $v$ calculated Larson-Miller curves for the alloys.

The calculated curves tend to underestimate alloy stressrupture life at combined high stress and high $P$ values, by a factor of two. This level of discrepancy is of the same order as normal test scatter. It does indicate however that the stress exponent decreases slightly more quickly at high stresses with rising temperature than equation 4 allows.

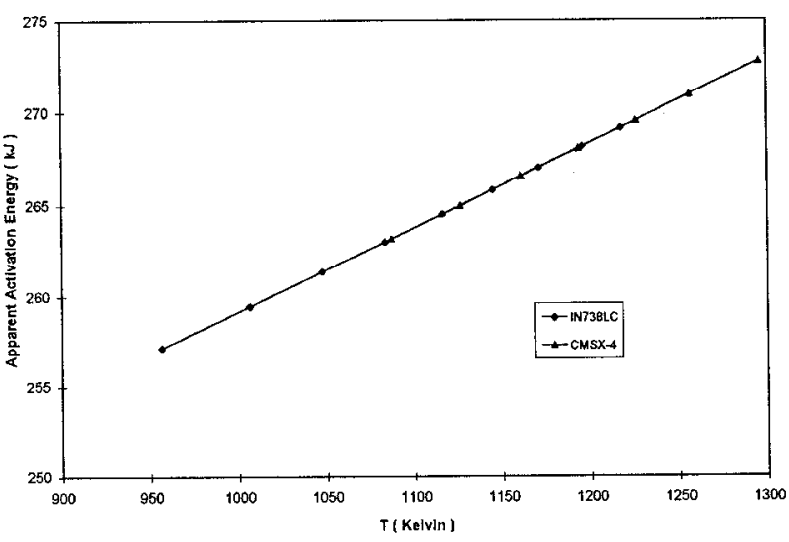

Fig.4 Dependence of apparent activation energy on temperature

\section{Conclusions}

A phase stability map has been constructed which describes the area within which superalloy chemistries should lie.

A single stress-rupture life $\mathrm{v}$ chemistry expression has been developed which predicts alloy performance over a working range of stress and temperature, for the alloys examined. Reliability will be improved as more alloys are added to the data-base.

Preliminary assessment of these two properties should enable a rapid selection of new chemistries for practical evaluation.

No attempt has been made in this report to establish alloy castability

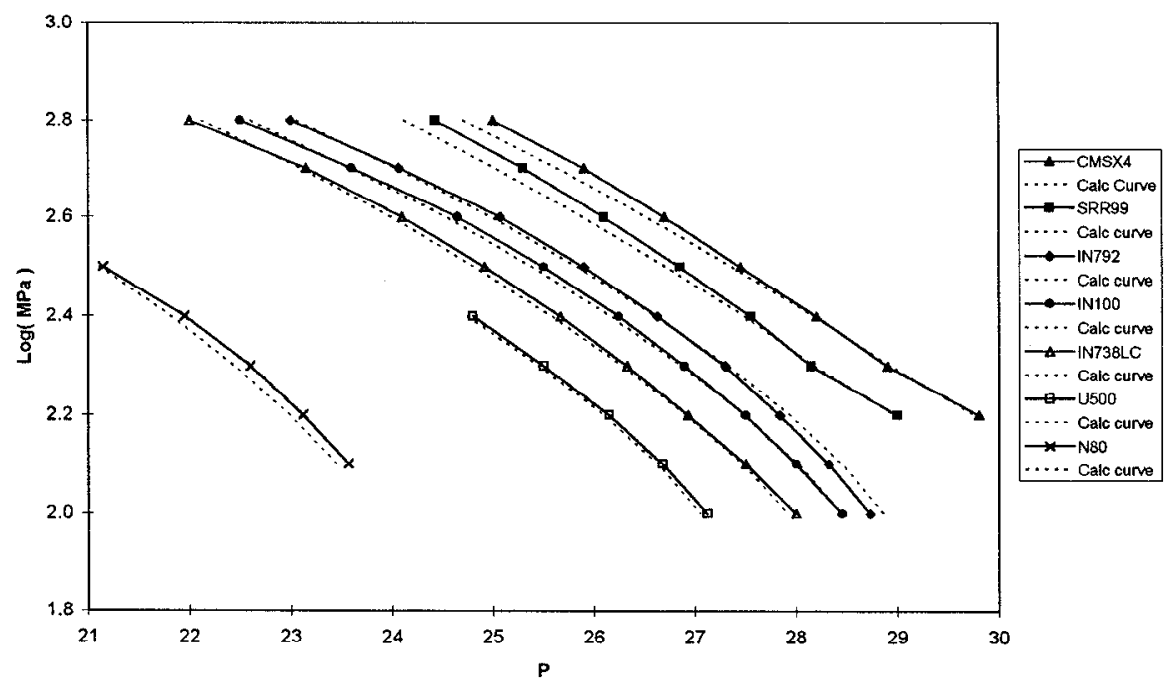

Fig.5 Comparison of calculated $\mathrm{v}$ actual Larson-Miller curves for various alloys. 


\section{References}

1. W.J.Boesch \& J.S.Slaney, Met. Prog. 86(1)(1964), 109

2. L.R.Woodyatt, C.T.Sims \& H.J.Beattie, Trans AIME, 236(1966), 519

3. N.Yukawa et al, Superalloys 1988 (Warrendale, PA: The Metallurgical Society, 1988), 225

4. K.Matsugi et al, Superalloys 1992 (Warrendale, PA: The Minerals, Metals \& Materials Society, 1992), 307

5. T.Lyman et al, eds., Metals Handbook, vol 1 (Metals Park, OH: American Society for Metals, 1985), 45

6. M.R.Winstone, "The Effect of Boron, Zirconium, Carbon \& Hafnium on the Structure \& Properties of Polycrystalline \& Single Crystal IN792", (Report TM79018, National Gas Turbine Establishment, May 1979) 